Mini-review

\title{
Dimerization inhibitors of HIV-1 reverse transcriptase, protease and integrase: A single mode of inhibition for the three HIV enzymes?
}

\author{
María-José Camarasa ${ }^{\mathrm{a}, *}$, Sonsoles Velázquez ${ }^{\mathrm{a}}$, Ana San-Félix ${ }^{\mathrm{a}}$, \\ María-Jesús Pérez-Pérez ${ }^{a}$, Federico Gago ${ }^{b}$ \\ ${ }^{a}$ Instituto de Química Médica (C.S.I.C.), Juan de la Cierva 3, 28006 Madrid, Spain \\ b Departamento de Farmacología, Universidad de Alcalá, 28871 Alcalá de Henares, Madrid, Spain \\ Received 17 February 2006; accepted 30 May 2006
}

Dedicated to Prof. Erik De Clercq on the occasion of reaching the status of Emeritus-Professor at the Katholieke Universiteit Leuven in September 2006.

\begin{abstract}
The genome of human immunodeficiency virus type 1 (HIV-1) encodes 15 distinct proteins, three of which provide essential enzymatic functions: a reverse transcriptase (RT), an integrase (IN), and a protease (PR). Since these enzymes are all homodimers, pseudohomodimers or multimers, disruption of protein-protein interactions in these retroviral enzymes may constitute an alternative way to achieve HIV-1 inhibition. A growing number of dimerization inhibitors for these enzymes is being reported. This mini review summarizes some approaches that have been followed for the development of compounds that inhibit those three enzymes by interfering with the dimerization interfaces between the enzyme subunits.

(C) 2006 Elsevier B.V. All rights reserved.
\end{abstract}

Keywords: HIV-1; Reverse transcriptase; Integrase; Protease

\section{Contents}

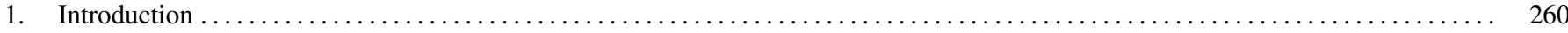

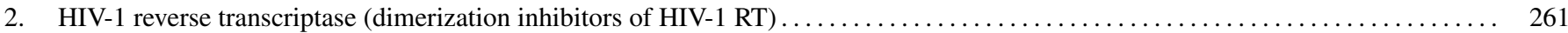

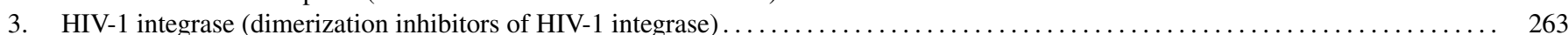

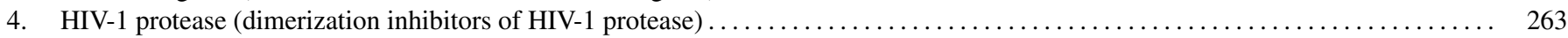

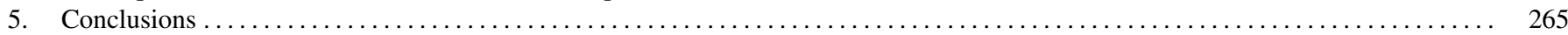

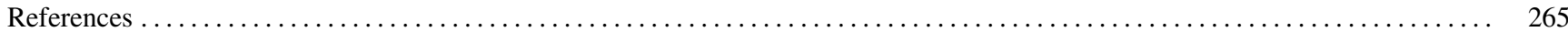

\section{Introduction}

Acquired immunodeficiency syndrome (AIDS), caused by human immunodeficiency virus infection, is still one of the most important challenges for the chemotherapy of the early 21 st century. HIV has killed more than 25 million people since it was first recognized in 1981. Despite the great efforts that are being devoted to prevent, treat and to better understand the disease, this is one of the main causes of morbidity and mortality worldwide, with different incidence in developing and non-developing countries. The number of drugs against this disease is slowly

\footnotetext{
* Corresponding author. Tel.: +34 915622900; fax: +34 915644853.

E-mail address: mj.camarasa@iqm.csic.es (M.-J. Camarasa).
}

increasing but the chemotherapy is far from being solved. The required long-term treatments are accompanied by adverse side effects, lack or difficulties in compliance with the arduous treatment protocols, and resistance development, which in turn may lead to the halt of the clinical treatment. This indicates that the "armamentarium" for the clinical treatment of HIV infection is not enough to control either viral replication or the appearance of viral resistant strains. Therefore, there is an urgent need for the development of new and safer drugs, active against the currently resistant viral strains or directed to novel targets in the viral replicative cycle, which may be useful for multiple drug combination.

The design of drugs directed against enzymes involved in pathological processes is a realistic and one of the most efficacious therapeutic options. Many of the top 100 drugs sold 


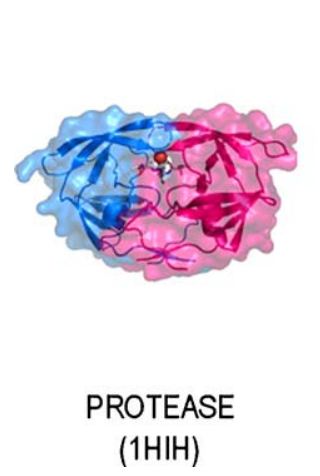

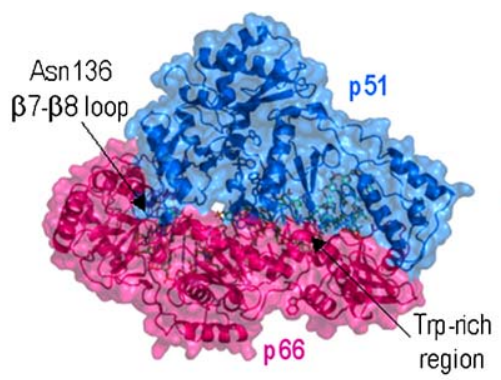

REVERSE TRANSCRIPTASE (1RTD)

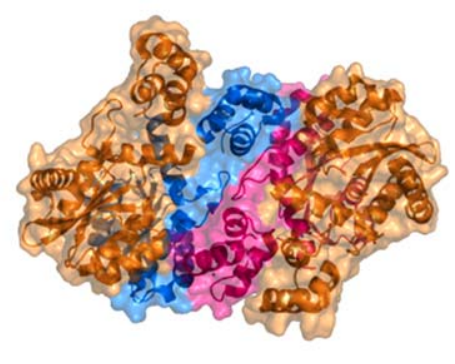

INTEGRASE

$(1 \mathrm{~K} 6 \mathrm{Y})$

Fig. 1. Ribbon representation of HIV-1 protease (left), reverse transcriptase (middle), and integrase (right) displayed using molecular graphics program PyMol (http://pymol.sourceforge.net/). Each subunit is enveloped by a semitransparent solvent-accessible surface that has been colored in either magenta or blue to highlight the dimerization interactions (For interpretation of the references to color in this figure legend, the reader is referred to the web version of the article.).

worldwide are enzyme inhibitors. While searching for novel more specific enzyme inhibitors, many efforts are being directed nowadays to inhibition modalities that are different from the interaction at the substrate-binding site (active site). In particular, small-molecule inhibitors of protein-protein interactions are receiving a great deal of attention (Keskin et al., 2005; Loregian et al., 2002; Loregian and Palù, 2005; Pommier and Cherfils, 2005; Toogood, 2002). This approach increases our understanding of the basic biological processes where the target enzymes are involved (ranging from intercellular communication to programmed cell death) and at the same time generates great opportunities for the identification of novel pharmaceuticals that can offer attractive opportunities for therapeutic intervention. Till very recently, it has been considered that protein-protein interactions were the result of the sum of numerous low energy point interactions. However, it is now commonly accepted that just a few of these contributions are crucial for the protein-protein interaction, that is, a significant contribution to the binding energy is localized in small regions that are designated as "hot spots" (Keskin et al., 2005). Nowadays it is accepted that small molecules are able to inhibit protein-protein interactions, and some examples of these kinds of inhibitors are used in the clinic (Jordan, 2002; Ockey and Gadek, 2002; Pommier and Cherfils, 2005; Toogood, 2002). Since these ligands do not need to be structurally related to substrates they could lead to safer and more efficacious drugs by overcoming selectivity issues and substrate competition issues.

The genome of human immunodeficiency virus type 1 (HIV1) encodes 15 distinct proteins (Frankel and Young, 1998), three of which provide essential enzymatic functions: a reverse transcriptase (RT), an integrase (IN), and a protease (PR). These three enzymes are all homodimers or pseudohomodimers. Due to the structural information available for HIV, and the importance of these enzymes for viral replication, a growing number of dimerization inhibitors for these enzymes is being reported. Therefore, disruption of protein-protein interactions in retroviral enzymes may constitute an alternative way to achieve HIV-1 inhibition.

This mini review summarizes some approaches that have been followed for the development of compounds that inhibit these enzymes by interfering with the dimerization interfaces between the enzyme subunits (Fig. 1).

\section{HIV-1 reverse transcriptase (dimerization inhibitors of HIV-1 RT)}

HIV-1 RT catalyzes an essential step in the replication of HIV-1, namely the synthesis of double-stranded DNA from the retroviral RNA genome. The biologically active form of the enzyme is an asymmetric heterodimer composed of two subunits of identical sequence named p66 and p51. The monomers are catalytically inert. The p66 subunit contains the catalytic site (a triad of aspartic acid residues) and both polymerase and RNase $\mathrm{H}$ activities, whereas the shorter $\mathrm{p} 51$ subunit lacks these functions but provides structural support to the p66 subunit. In fact, p51 has an impact on the catalytic activity of the enzyme (Divita et al., 1995) because it is essential for loading the p66 subunit on the template primer (Harris et al., 1998). For the process of native dimerization between p66 and p51 a two-step model has been proposed (Basu et al., 1992). The first step involves a concentration-dependent association of both subunits (p66 and p51) resulting in an inactive intermediate, which slowly isomerizes to the "mature" heterodimeric form of the enzyme in a second step (Divita et al., 1993). The dimerization is essential for a fully functional RT. The dimeric form of the enzyme is an absolute requirement for all enzymatic activities (Müller et al., 1989; Restle et al., 1990, 1992). Therefore, dimerization is essential for a fully functional RT (Restle et al., 1990) and this process offers an excellent opportunity to inhibit the enzyme by a different mechanism from those described so far, that is, by disrupting a key protein-protein interaction. Among the advantages of this kind of inhibitors are an expected higher specificity and a lower risk of selection of drug-resistant strains, since mutations at the p66-p51 interface will hamper the association process and thus may compromise the catalytic activity of the enzyme (Auwerx et al., 2005a,b; Balzarini et al., 2005).

There are three major contact areas in the dimer interface between the p66 and p51 subunits (Becerra et al., 1991) in HIV$1 \mathrm{RT}$, namely the fingers subdomain of p51 with the palm of $\mathrm{p} 66$, the connection subdomains of both subunits, and the thumb 
domain of p51 with the RNase H domain of p66 (Kohlstaedt et al., 1992; Huang et al., 1998). The most intensively studied interface area between p66 and p51 is the tryptophan-rich amino acid stretch in the connection subdomain of both RT subunits, consisting of six tryptophan residues at codons 398, 401, 402, 406, 410 , and 414 (which are highly conserved amongst all primate lentiviral RTs). These amino acids play an important role in RT dimerization (Harris et al., 1998; Müller et al., 1989), mediated mainly through the p66 subunit.

The first attempts to develop dimerization inhibitors of HIV-1 RT consisted on the synthesis of peptides mimicking the major contacts between the p66 and p51 subunits, in order to prevent heterodimer formation (Baillon et al., 1991; Divita et al., 1993). Thus, synthetic tryptophan-rich peptides of 19 and 10 residues derived from a sequence within the tryptophan-rich amino acid stretch (positions 384-407) were inhibitors of HIV-1 RT dimerization (Divita et al., 1994, 1995; Morris et al., 1999; Restle et al., 1990). The decapeptide was shown to interact preferentially with the p51 subunit of the heterodimeric HIV-1 RT, in a cleft between the fingers and the connection subdomains of p51 that contains the two highly conserved Phe61 and Trp24 residues (Depollier et al., 2005). As a consequence, the peptide destabilizes the dimer conformation and triggers dissociation.

Another motif is suggested to be involved in RT dimerization. $\mathrm{RT}$ is a central region that contains the leucine hepta-repeat motif (Leu282-Leu310) in the p66 subunit (Becerra et al., 1991; Goel et al., 1993).

Finally, a third important region of the p66/p51 dimer interface is the $\beta 7-\beta 8$ loop in p51 that forms the "floor" of the non-nucleoside reverse transcriptase inhibitor (NNRTI) binding pocket and fits in a groove-like structure that constitutes the template/primer binding site in the p66 subunit (Restle et al., 1990; Harris et al., 1998). This loop of the p51 subunit is essential for the catalytic function on the p66 subunit (Pandey et al., 2001, 2002), and its presence is an absolute requirement for RT dimerization (Pandey et al., 2002).

With respect to the interaction of drugs at the p66-p51 dimer interface, it is noteworthy that exposure of HIV-1 RT with TSAO molecules (whose prototype compound is the thymine derivative, TSAO-T (1), a peculiar family of non-nucleoside reverse transcriptase inhibitors developed by our group in collaboration with the group of Drs. Jan Balzarini and Erik De Clercq at the Rega Institute of Leuven (Belgium) (Balzarini et al., 1992; Camarasa et al., 1992, 2004), has been shown to destabilize the heterodimeric RT leading to a loss in its ability to bind DNA (Sluis-Cremer et al., 2000). Remarkably, this effect has not been observed with any other NNRTI. Thus, TSAO-T represents the first example of a small non-peptidic molecule able to interfere with the dimerization process of HIV-1 RT (Sluis-Cremer et al., 2000).

In the absence of experimentally solved crystallographic structures, computational docking studies led us to propose a binding mode for TSAO derivatives with HIV-1 RT (RodríguezBarrios et al., 2001) distinct from that of "classical" NNRTIs. According to this model, TSAO derivatives make extensive use of the $\beta 7 / \beta 8$ loop of the p51 subunit, which is consistent with the fact that site-directed mutagenesis and resistance studies have shown that this glutamic acid residue is the key interaction point for TSAO binding (Boyer et al., 1994; Jonckheere et al., 1994). Moreover, the $\beta 7-\beta 8$ loop of the p51 subunit was computationally identified as a "hot spot" for dimerization (Rodríguez-Barrios et al., 2001) strongly suggesting that it may constitute by itself a novel pharmacological target for RT inhibition. Indeed, recent studies have provided experimental evidence that this loop in the p51 subunit is essential for RT dimerization and catalytic efficiency of the p66 subunit (Auwerx et al., 2005a,b; Balzarini et al., 2005; Pandey et al., 2002).

According to the proposed mode of binding to HIV-1 RT for TSAO derivatives (Rodríguez-Barrios et al., 2001), the most buried part of the molecule is the spiroaminosultone moiety, while the substituents on the N-3 position of the thymine base are relatively exposed and they run parallel to the subunit interface. For these reasons, we considered chemical modifications at these two positions in the prototype compound, TSAO-T, as the most crucial to study the possible impact on RT dimerization. In addition, to improve the interactions with neighbouring amino acids from both subunits, different functional groups were introduced at position $3^{\prime \prime}$ of the spiro ring (Lobatón et al., 2002). In general, the compounds showed pronounced antiHIV-1 activity, although lower than that of TSAO-T and they also turned out to be much more toxic. Studies on the effect of these $3^{\prime \prime}$-TSAO modified compounds on RT dimerization indicate that compound $\mathbf{2}$ seems to have a higher destabilizing effect dimerization than TSAO-T (unpublished results). In the series of TSAO compounds bearing different carbonyl functionalities at the $4^{\prime \prime}$-position (de Castro et al., 2005), many analogues showed high anti-HIV-1 activity against viral replication, but these $4^{\prime \prime}$ TSAO modified compounds did not show any improvement over the parent TSAO-T as dimerization inhibitors (unpublished results). On the other hand, substitutions at the N-3 position of the thymine base led to compounds endowed with a greater impact on RT dimerization (Bonache et al., 2005) suggesting that interactions with one or more of the dimer interface residues close to the TSAO binding site (Glu138) may help destabilize the RT dimer by disrupting key interface interactions.

Virtually all synthesized N-3-substituted TSAO derivatives showed marked anti-HIV-1 activities (in the nanomolar range). The best compounds $\left(\mathrm{EC}_{50}=10-30 \mathrm{nM}\right)$ were those bearing at $\mathrm{N}-3$ an alcohol (3) or $N$-methylcarboxamide (4) groups. The $N$-3 methylcarboxamide TSAO derivative 4 showed a superior effect on HIV-RT dimerization than TSAO-T (unpublished results). To explain the increased activity of $\mathbf{3}$ and $\mathbf{4}$ the N-3substituted compounds were docked into our proposed binding site at the p66-p51 dimer interface (Rodríguez-Barrios et al., 2001). According to the docking model, the improved activity of compound $\mathbf{3}$ could be explained by the establishment of an additional hydrogen bond between the attached $\left(\mathrm{CH}_{2}\right)_{3}-\mathrm{OH}$ group at the N-3 position of TSAO-T and the carbonyl group of Pro-B140 in the p51 subunit of the enzyme. On the other hand, the resulting model showed the $N-3$ methyl carboxamide moiety of 4 running parallel to the subunit interface could likewise form two hydrogen bonds with the enzyme (Bonache et al., 2005), one 


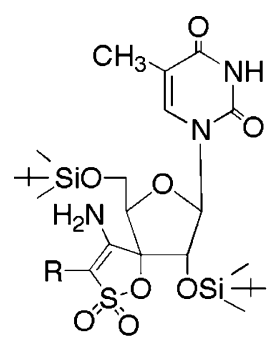

$1 \mathrm{R}=\mathrm{H}, \mathrm{TSAO}-\mathrm{T}$ $2 \mathrm{R}=\mathrm{I}$

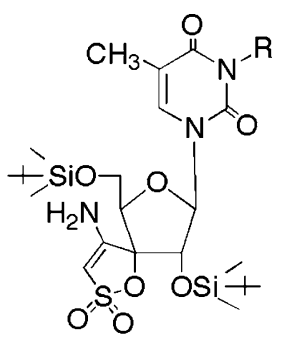

$3 \mathrm{R}=\left(\mathrm{CH}_{2}\right)_{3} \mathrm{OH}$

$4 \mathrm{R}=\left(\mathrm{CH}_{2}\right)_{4} \mathrm{CONHCH}_{3}$

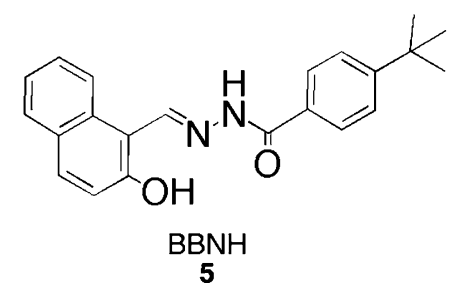

Fig. 2. Examples of TSAO derivatives and structure of BBNH (HIV-1 RT dimerization inhibitors).

between the amide nitrogen of $\mathbf{4}$ and the main-chain carbonyl oxygen of Pro-B140 and a second one between the amide carbonyl and the terminal amino group of the side chain of Lys-B49. The additional stabilization gained from these extra interactions might explain why 4 turns out to be a 6-fold better inhibitor than TSAO- $\mathrm{m}^{3} \mathrm{~T}$. This outcome is fully consistent with the prediction that additional interactions at or near the p51-p66 interface could result in compounds with improved binding affinity over the prototype TSAO-T (Rodríguez-Barrios et al., 2001) (Fig. 2).

Regarding other small molecules that seem to have some impact on HIV-1 RT dimerization, BBNH (5), a multitarget inhibitor of HIV-1 RT (Arion et al., 2002; Borkow et al., 1997), was also found to decrease the dimeric stability of RT (SluisCremer et al., 2002). On the other hand, it has recently been reported that several NNRTIs enhance enzyme dimerization (Sluis-Cremer et al., 2000, 2002; Sluis-Cremer and Tachedjian, 2002; Tachedjian and Goff, 2003; Tachedjian et al., 2001).

\section{HIV-1 integrase (dimerization inhibitors of HIV-1 integrase)}

HIV integrase catalyzes the insertion and integration of viral DNA into the host genome. This essential enzyme, which is required for viral replication, has no counterpart in the host cell. The structure and function of HIV-1 integrase have been recently reviewed (Asante-Appiah and Skalka, 1999; Chiu and Davies, 2004; Pommier and Cherfils, 2005). HIV-1 IN is a $32 \mathrm{kDa}$ protein that comprises three independently folded domains (Engelman and Craigie, 1992; Engelman et al., 1993; Katzman and Sudol, 1995), the N-terminal domain (residues 1-50) characterized by a conserved HHCC zinc binding motif (Cai et al., 1997), the dimeric catalytic core domain (residues 50-212) and the Cterminal domain (residues 213-288), involved in non-specific DNA binding (Lutzke and Plasterk, 1998). Up to now structure of the whole integrase is not available. Structural and functional studies show that individual functional domains or two-domains IN molecules form dimers themselves. However, in vivo and in vitro complementation studies suggest that the active HIV IN is a multimer (at least a tetramer) (Engelman et al., 1993; Esposito and Craigie, 1999; Wang et al., 2001). Moreover, the current results suggest that the whole integrase might be a homodimer. The dimerization interface is made of four $\alpha$ helices $(\alpha 1, \alpha 3, \alpha 5$, $\alpha 6$ ) and one $\beta$ strand ( $\beta 3$ ) from each monomer in the catalytic core domain and is stabilized by additional subunit interface interactions (residues 29-35 from the N-terminal domain) in the N-terminal catalytic core (Chen et al., 2000; Sluis-Cremer and Tachedjian, 2002).

Peptide-based inhibitors derived from the dimeric interface of the HIV-1 IN enzyme, have been designed and synthesized (Lutzke et al., 1995). Thus, Sourgen et al. (1996) described two synthetic peptides containing the residues $147-175$ of the HIV$1 \mathrm{IN}$, and the same sequence but with Lys159 replaced by a proline. Only the first one showed an in vitro inhibitory effect on strand transfer, $3^{\prime}$ processing and autointegration activities. However, it is not clear whether this activity is due to interference with the dimerization interface of integrase. Maroun et al. (2001) described peptides INH1 (which mimics the amino acid sequence of $\alpha 1$ helix, 17 residues from amino acids 93-107) and INH5 (which incorporates the $\alpha 5$ helix and part of the loop separating the $\alpha 4$ and $\alpha 5$ helices, 21 residues from amino acids 167-187), both derived from the sequences of the $\alpha 1$ and $\alpha 5$ helices of the catalytic core. These peptides inhibited the strand transfer activity of the enzyme with $\mathrm{IC}_{50}$ values in the $\mathrm{nM}$ range, being INH5 a better inhibitor than INH1. Both peptides perturbed the association-dissociation equilibrium of the whole enzyme and catalytic cores. Zhao et al. (2003) synthesized five interfacial peptides derived from the dimeric interface of HIV-1 IN. The peptide sequences correspond to the five regions of the catalytic domain $(\alpha 1, \alpha 3, \alpha 5, \alpha 6$, and $\beta 3)$. All peptides were found to adopt a random coil conformation in aqueous solution, as assessed by circular dichroism. Three peptides $(\alpha 1, \alpha 5$, and $\alpha 6$ ) were inhibitors of 3 -endonuclease activity of the enzyme, with $\mathrm{IC}_{50}$ values in the $\mu \mathrm{M}$ range and were able to disrupt the crosslinking of the IN dimer.

Indolicidin, a natural antimicrobial peptide, was found to have IN inhibitory activity. Further analogues of indolicidin with short peptidic sequences (hexapeptides) showed improved activity (Robinson et al., 1998). Krajewski et al. (2003, 2004) prepared dimers and tetramers by connecting the monomers' Cterminal ends using different linkers. The tetramers proved to be more potent than dimeric peptides in both $3^{\prime}$-end processing and strand transfer assays. These peptides seem to act as multimeric inhibitors that bind simultaneously to two or four neighbouring catalytic sites within the integrase oligomeric complex.

\section{HIV-1 protease (dimerization inhibitors of HIV-1 protease)}

HIV-1 protease is the enzyme responsible for the posttranslational processing of viral polyproteins and subsequent generation of the structural and functional proteins essential for viral replication (Oroszlan and Luftig, 1990). 
The fact that this step is essential for maturation of the virus and production of infectious particles accounts for the early (Huff, 1991; Wlodawer and Erickson, 1993) and current interest (Gago, 1999; Lebon and LeClecq, 2000; Priestle et al., 1995; Tomasselli and Heinrikson, 2000) in HIV protease as a prime target for antiretroviral drug design. HIV PR is a homodimeric aspartyl protease with each monomer having 99 residues. The active site is located at the bottom of a cavity in the dimer interface and is covered by two $\beta$-hairpins, called "flaps", one from each monomer that are very flexible (Wlodawer et al., 1989), most likely to facilitate substrate binding and product release, and participate in the binding of inhibitors (Nicholson et al., 1995). Since each monomer contributes one of the two catalytic aspartic acid residues (Asp25) the monomers are catalytically inert and dissociation of the enzyme homodimer results in a complete loss of catalytic activity. Each active site triad Asp25-Thr26-Gly27 is located in a loop whose structure is stabilized by a "firearm's grip" network of hydrogen bonds. As a result, the carboxylic groups of Asp25 from both subunits, which may have different ionization states depending on whether or not an inhibitor is bound to the enzyme (Smith et al., 1996), are positioned very close together and in a nearly coplanar arrangement.

The homodimeric nature of HIV-1PR suggests that enzyme inhibition could be accomplished by preventing the selfassembly of the biologically active dimer in infected cells as an alternative to the use of substrate analogues. A large part of the dimerization interface (a four stranded $\beta$-sheet) is made up of an interdigitation of the $\mathrm{N}$ - and C-terminal portions of each monomer (residues 1-4 and 96-99). Since this region appears to be highly conserved among HIV-1 isolates, it stands out as an attractive target that is quite distinct from the substrate-binding cavity. In fact, the proof of concept for the feasibility of this hypothesis was obtained as early as 1991 when peptides corresponding to the $\mathrm{N}$ - and $\mathrm{C}$-termini of HIVp were shown to effectively inhibit enzyme activity (Schramm et al., 1991; Zhang et al., 1991), albeit at micromolar concentrations. In one of the first examples of dissociative inhibition, kinetic analysis showed that the tetrapeptide Ac-Thr-Leu-Asn-Phe-COOH, corresponding to the $\mathrm{COOH}$-terminal segment of the enzyme, was able to bind to the inactive protomers and prevent their association into the active dimer (Sluis-Cremer and Tachedjian, 2002). Further interference with dimer assembly has been achieved, among others (Babé et al., 1992), by contiguous peptide sequences containing the N- and C-terminal regions of HIV PR linked with a $3.5 \AA$ tether composed of three glycine residues (Zutshi et al., 1997) and by covalently crosslinked N-terminal HIVp peptides (Park and Raines, 2000).

Peptides with affinity for the interfacial surface of HIV proteases constituent monomers have been sought also using a genetic selection approach. By fusing a non-catalytically active D25N HIV PR variant to the DNA-binding domain of the repressor protein from bacteriophage $\lambda$, a hybrid repressor was generated that allowed high-throughput screening of a library of $5 \times 10^{8}$ peptides with nine random amino acid residues. Less than one peptide in $10^{6}$ was found to be able to disrupt HIV PR monomer association and in those identified there was an abundance of non-polar residues, especially valine, alanine, and glycine (Fan et al., 1998). Addition of a cysteine residue to the C-terminus of one of these peptides and crosslinking with the homobifunctional reagent 1,6-hexane-bis-vinylsulfone, led to a 40-fold more potent dissociative inhibitor (dissociative inhibition constant of $0.8 \mu \mathrm{M}$ ) (Fig. 3).

Similar low-micromolar, non-competitive or dissociative inhibition constants have been reported for a few non-peptidic natural products and derivatives, most significantly some triterpenes (e.g. ursolic acid) identified through a pharmacophorebased computer search of the Cambridge Structural Database, and several simplified pentaester derivatives of didemnaketals A and B (first isolated from a marine ascidian belonging to the genus Didemnum) (Fan et al., 1998).
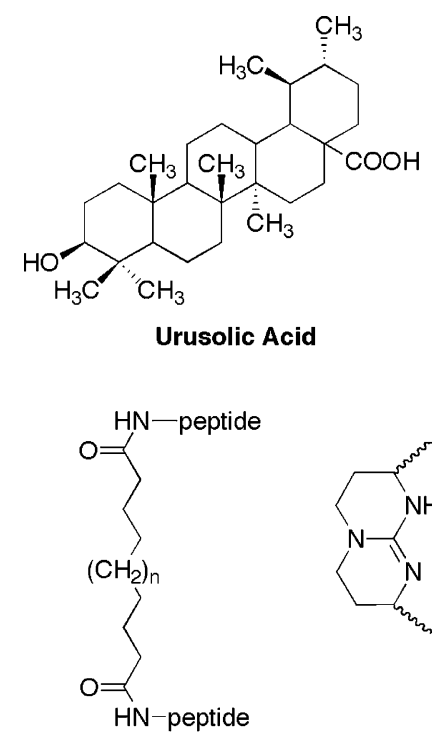

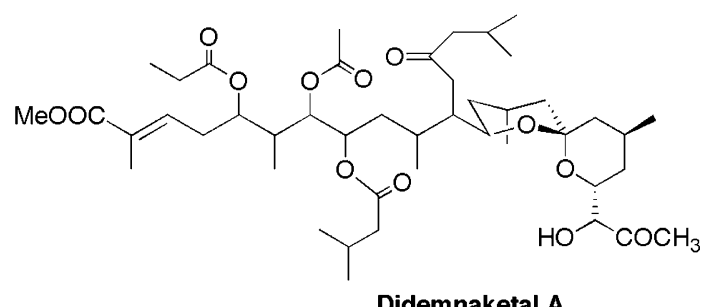

Didemnaketal A

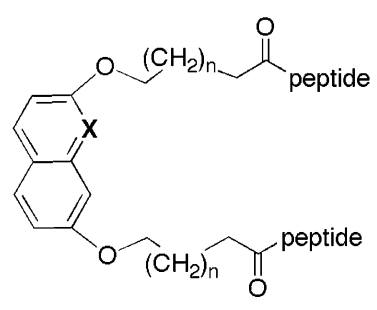

"Molecular Tongs"

Fig. 3. Examples of compounds reported to be able to prevent HIV PR monomer association or promote dimer dissociation. 
Irreversible inhibitors of HIV PR have been also described. Thus, an interface binding peptide able to form a disulfide bond with Cys95, present at the dimerization interface of HIV-1 PR (Zutshi and Chmielewski, 2000) proved to be a potent crosslinking inhibitor of HIV-1 protease ( $K_{\text {inac }}$ of $\left.3.7 \mu \mathrm{M}\right)$.

As described here so far, strategies for developing new inhibitors using interfacial peptides derived from the $\mathrm{N}$ - or C-terminal segments have been applied successfully in several studies (Schramm et al., 1991, 1993, 1996). This work suggests that short peptides derived from these segments are able to interrupt homodimer formation by non-covalent dissociative inhibition. Covalently cross-linked interfacial peptides from each $\mathrm{N}$ - and $\mathrm{C}$-terminus of the protease designed to bridge two peptide chains using flexible tether molecules, inhibited protease activity and decreased the amount of protease dimer in solution (Schramm et al., 1996; Hwang and Chmielewski, 2004). Bouras et al. (1999) introduced a more rigid scaffold in the tether (to increase the conformational constrain), called "molecular tongs" such as resorcinol, 2,6-pyridinediol and 2,7naphthalenediol, leading compounds active in the micro and submicromalor range. Merabet et al. (2004) introduced "new molecular tongs" based on quinoline and naphtalene scaffolds linked to two peptidic strands of different sequence. Some of the compounds prepared acted as dimerization inhibitors at submicromolar concentrations. Song et al. (2001) introduced new conformationally constrained templates such as a " $\beta$-sheet nucleator" that connects the interfacial $\mathrm{N}$ - and $\mathrm{C}$ terminal peptide fragments from the protease sequence and an "unnatural $\beta$-strand mimetic", which interferes with the $\beta$ sheet interaction between two monomers and inhibits enzymatic activity.

Dimerization inhibitors of HIV-1 PR based on a chiral lipophilic bicyclic guanidinium subunit as the central tether between a short peptide mimicking the C-terminal native strand, to interact with both $\mathrm{C}$ and $\mathrm{N}$ termini of the monomer, and an additional hydrophobic bulky group (TBDPS, Cholesteryl) targeting the dimer interface have also been described (Breccia et al., 2003). Some of the compounds described inhibited the dimerization of HIV PR in the nanomolar range $\left(K_{\text {id }}=150-400 \mathrm{nM}\right)$.

\section{Conclusions}

The field of interfacial binding inhibitors for fighting against HIV is still in its infancy but new techniques are being developed that will hopefully provide some guidelines for the design of novel drug candidates. This approach is clearly more challenging than others aimed at identifying ligands that will bind to preorganized small pockets meant for binding natural small molecules but the outcome of these efforts can be highly rewarding. The three protein-protein interfaces present in RT, IN, and HIVp are likely to pose different problems and this will affect their tractability. Nonetheless, it can be anticipated that affinities will be improved if two or more weak binding ligands can be covalently linked or, alternatively, if a reactive functional group can be incorporated into a given specific non-covalent ligand.

\section{References}

Arion, D., Sluis-Cremer, N., Min, K.L., Abram, M.E., Fletcher, R.S., Parniak, M.A., 2002. Mutational analysis of Tyr-501 of HIV-1 reverse transcriptase. Effects on ribonuclease $\mathrm{H}$ activity and inhibition of this activity by $N$-acylhydrazones. J. Biol. Chem. 277, 1370-1374.

Asante-Appiah, E., Skalka, A.M., 1999. HIV-1 integrase: structural organization, conformational changes, and catalysis. Adv. Virus Res. 52, 351-369.

Auwerx, J., Rodríguez-Barrios, F., Ceccherini-Silberstein, F., San Félix, A., Velázquez, S., De Clercq, E., Camarasa, M.J., Perno, C.F., Gago, F., Balzarini, J., 2005a. Role of T139 in the human immunodeficiency virus type 1 (HIV-1) reverse transcriptase (RT) sensitivity to (+)-calanolide A. Mol. Pharmacol. 68, 652-659.

Auwerx, J., Van Nieuwenhove, J., Rodríguez-Barrios, F., de Castro, S., Velázquez, S., Ceccherini-Silberstein, F., De Clercq, E., Camarasa, M.J., Perno, C.F., Gago, F., Balzarini, J., 2005b. The N137 and P140 amino acids in the p51 and the P95 amino acid in the p66 subunit of human immunodeficiency virus type 1 reverse transcriptase (RT) are instrumental to maintain the polymerase activity and are prime targets for the rational design of new classes of anti HIV-1 RT drugs. FEBS Lett. 579, 2294-2300.

Babé, L.M., Rose, J., Craik, C.S., 1992. Synthetic "interface" peptides alter dimeric assembly of the HIV 1 and 2 proteases. Protein Sci. 1, $1244-1253$

Baillon, J.G., Nashed, N.T., Kumar, A., Wilson, S.H., Jerina, D.M., 1991. A leucine zipper-like motif may mediate HIV reverse transcriptase subunit binding. New Biol. 3, 1015-1019.

Balzarini, J., Pérez-Pérez, M.J., San-Félix, A., Schols, D., Perno, C.F., Vandamme, A.M., Camarasa, M.J., De Clercq, E., 1992. $2^{\prime}, 5^{\prime}$-Bis-O-(tert-butyldimethylsilyl)-3'-spiro-5" - $^{\prime \prime} 4^{\prime \prime}$-amino-1" ${ }^{\prime \prime}, 2^{\prime \prime}$ oxathiole-2",2-dioxide)pyrimidine (TSAO) nucleoside analogues: highly selective inhibitors of human immunodeficiency virus type 1 that are targeted at the viral reverse transcriptase. Proc. Natl. Acad. Sci. U.S.A. 89, 4392-4396

Balzarini, J., Auwerx, J., Rodríguez-Barrios, F., Chedad, A., Farkas, V., Ceccherini-Silberstein, F., García-Aparicio, C., Velázquez, S., De Clercq, E., Perno, C.F., Camarasa, M.J., Gago, F., 2005. The amino acid N136 in HIV-1 reverse transcriptase (RT) maintains efficient association of both Rtsubunits and enables the rational design of novel RT inhibitors. Mol. Pharmacol. 68, 49-60.

Basu, A., Basu, S., Modak, M.J., 1992. Structure-activity analyses of HIV-1 reverse transcriptase. Biochem. Biophys. Res. Commun. 183, 1131-1138.

Becerra, S.P., Kumar, A., Lewis, M.S., Widen, S.G., Abbotts, J., Karawya, E.M., Hughes, S.H., Shiloach, J., Wilson, S.H., 1991. Protein-protein interactions of HIV-1 reverse transcriptase: implications of central and C-terminal regions in subunit binding. Biochemistry 30, $11707-11719$.

Bonache, M.C., Chamorro, C., Velázquez, S., De Clercq, E., Balzarini, J., Rodríguez-Barrios, F., Gago, F., Camarasa, M.J., San-Félix, A., 2005. Improving the antiviral efficacy and selectivity of HIV-1 reverse transcriptase inhibitor TSAO-T by the introduction of functional groups at the N-3 position. J. Med. Chem. 48, 6653-6660.

Borkow, G., Fletcher, R.S., Barnard, J., Arion, D., Motakis, D., Dmitrienko, G.I., Parniak, M.A., 1997. Inhibition of the ribonuclease $\mathrm{H}$ and DNA polymerase activities of HIV-1 reverse transcriptase by $N$-(4-tertbutylbenzoyl)-2-hydroxy-1-naphthaldehyde hydrazone. Biochemistry 36 , 3179-3185.

Bouras, A., Boggetto, N., Benatalah, Z., de Rosny, E., Sicsic, S., ReboudRovaux, M., 1999. Design, synthesis and evaluation of conformationally constrained tongs, new inhibitors of HIV-1 protease dimerization. J. Med. Chem. 42, 957-962.

Boyer, P.L., Ding, J., Arnold, E., Hughes, S.H., 1994. Subunit specificity of mutations that confer resistance to nonnucleoside inhibitors in human immunodeficiency virus type 1 reverse transcriptase. Antimicrob. Agents Chemother. 38, 1909-1914.

Breccia, P., Boggetto, N., Pérez-Frenández, R., Van Gool, M., Takahashi, M., René, L., Prados, P., Badet, B., Rebond-Ravaux, M., De Mendoza, 
J., 2003. Dimerization inhibitors of HIV-1 protease based on a bicyclic guanidinium subunit. J. Med. Chem. 46, 5196-5207.

Cai, M., Zheng, R., Caffrey, M., Craigee, R., Clore, G.M., Gronenborn, A.M., 1997. Solution structure of the N-terminal zinc binding domain of HIV-1 integrase. Nat. Struct. Biol. 4, 567-577 (Erratum in Nat. Struct. Biol. 4 (1997) 839-840).

Camarasa, M.J., Pérez-Pérez, M.J., San-Félix, A., Balzarini, J., De Clercq, E., 1992. 3'-Spironucleosides a new class of specific human immunodeficiency virus type 1 inhibitors: synthesis and antiviral activity of [2',5'-bis- $O$-(tert-butyldimethylsilyl)- $\beta$-D-xylo and ribofuranose]-3'-spiro$5^{\prime \prime}$-[4" -amino- $1^{\prime \prime}, 2^{\prime \prime}$-oxathiole- $2^{\prime \prime}, 2^{\prime \prime}$-dioxide] (TSAO) pyrimidine nucleosides. J. Med. Chem. 35, 2721-2727.

Camarasa, M.J., San-Félix, A., Velázquez, S., Pérez-Pérez, M.J., Gago, F., Balzarini, J., 2004. TSAO compounds: the comprehensive story of a unique family of HIV-1 specific inhibitors of reverse transcriptase. Curr. Top. Med. Chem. 4, 945-963.

de Castro, S., Lobatón, E., Pérez-Pérez, M.J., San-Félix, A., Cordeiro, A., Andrei, G., Snoeck, R., De Clercq, E., Balzarini, J., Camarasa, M.J., Velázquez, S., 2005. Novel $\left[2^{\prime}, 5^{\prime}\right.$-bis- $O$-(tert-butyldimethylsilyl)$\beta$-D-ribofuranosyl]- $3^{\prime}$-spiro- $5^{\prime \prime}$-(4"-amino- $1^{\prime \prime}, 2^{\prime \prime}$-oxathiole-2", $2^{\prime \prime}$-dioxide) derivatives with anti-HIV-1 and anti-human-cytomegalovirus activity. J. Med. Chem. 48, 1158-1168.

Chen, J.C., Krucinskji, J., Miercke, L.J., Finer-Moore, J.S., Tang, A.H., Leavitt, A.D., Stroud, R.M., 2000. Crystal structure of the HIV-1 integrase catalytic core and C-terminal domains: a model for viral DNA binding. Proc. Natl. Acad. Sci. U.S.A. 97, 8233-8238.

Chiu, T.K., Davies, D.R., 2004. Structure and function of HIV-1 integrase. Curr. Top. Med. Chem. 4, 965-979.

Depollier, J., Hourdou, M.L., Aldrian-Herrada, G., Rothwell, P., Restle, T., Divita, G., 2005. Insight into the mechanism of a peptide inhibitor of HIV reverse transcriptase dimerization. Biochemistry 44, 1909-1918.

Divita, G., Restle, T., Goody, R.S., 1993. Characterization of the dimerization process of HIV-1 reverse transcriptase heterodimer using intrinsic protein fluorescence. FEBS Lett. 324, 153-158.

Divita, G., Restle, T., Goody, R.S., Chermann, J.C., Baillon, J.G., 1994. Inhibition of human immunodeficiency virus type 1 reverse transcriptase dimerization using synthetic peptides derived from the connection domain. J. Biol. Chem. 269, 13080-13083.

Divita, G., Rittinger, K., Geourjon, C., Deleage, G., Goody, R.S., 1995. Dimerization kinetics of HIV-1 and HIV-2 reverse transcriptase: a two step process. J. Mol. Biol. 245, 508-521.

Engelman, A., Bushman, F.D., Craige, R., 1993. Identification of discrete function domains of HIV-1 integrase and their organization within an active multimeric complex. EMBO J. 12, 3269-3275.

Engelman, A., Craigie, R., 1992. Identification of conserved amino-acidresidues critical for human-immunodeficiency-virus type-1 integrase function-in vitro. J. Virol. 66, 6361-6369.

Esposito, D., Craigie, R., 1999. HIV integrase structure and function. Adv. Virus Res. 52, 319-333.

Fan, X., Flentke, G.R., Rich, D.H., 1998. Inhibition of HIV-1 protease by a subunit of didemnaketal A. J. Am. Chem. Soc. 120, 8893-8894.

Frankel, A.D., Young, J.A.T., 1998. HIV-1: fifteen proteins and an RNA. Annu. Rev. Biochem. 67, 1-25.

Gago, F., 1999. Targeting HIV-1 protease: from peptidomimetics to nonpeptide inhibitors. IDrugs 2, 309-320.

Goel, R., Beard, W.A., Kumar, A., Casas-Finet, J.R., Strub, M.P., Stahl, S.J., Lewis, M.S., Bebenek, K., Becerra, S.P., Kunkel, T.A., Wilson, S.H., 1993. Structure/function studies of HIV-1 reverse transcriptase: dimerization-defective mutant L289K. Biochemistry 32, 13012-13018.

Harris, D., Lee, R., Misra, H.S., Pandey, P.K., Pandey, V.N., 1998. The p51 subunit of human immunodeficiency virus type 1 reverse transcriptase is essential in loading the p66 subunit on the template primer. Biochemistry 37, 5903-5908.

Huff, J.R., 1991. HIV protease: a novel chemotherapeutic target for AIDS. J. Med. Chem. 34, 2305-2314.

Huang, H., Chopra, R., Verdine, G.L., Harrison, S.C., 1998. Structure of a covalently trapped catalytic complex of HIV-1 reverse transcriptase: implications for drug resistance. Science 282, 1669-1675.
Hwang, Y.S., Chmielewski, J., 2004. A unidirectional crosslinking strategy for HIV-1 protease dimerization inhibitors. Bioorg. Med. Chem. Lett. 14, 4297-4300.

Jonckheere, H., Taymans, J.M., Balzarini, J., Velázquez, S., Camarasa, M.J., Desmyter, J., De Clercq, E., Anne, J., 1994. Resistance of HIV-1 reverse transcriptase against $\left[2^{\prime}, 5^{\prime}\right.$-bis- $O$-(tert-butyldimethylsilyl)- $3^{\prime}$-spiro- $5^{\prime \prime}$ - $\left(4^{\prime \prime}\right.$ amino- $1^{\prime \prime}, 2^{\prime \prime}$-oxathiole- $2^{\prime \prime}, 2^{\prime \prime}$-dioxide)] (TSAO) derivatives is determined by the mutation Glu138 $\rightarrow$ Lys on the p51 subunit. J. Biol. Chem. 269, 25255-25258.

Jordan, M.A., 2002. Mechanism of action of antitumor drugs that interact with microtubules and tubulin. Curr. Med. Chem. Anti-Cancer Agents 2, $1-17$.

Katzman, M., Sudol, M., 1995. Mapping domains of retroviral integrase responsible for viral-DNA specificity and target site selection by analysis of chimeras between human-immunodeficiency-virus type-1 and visna virus integrases. J. Virol. 69, 5687-5696.

Keskin, O., Ma, B.Y., Nussinov, R., 2005. Hot regions in protein-protein interactions: the organization and contribution of structurally conserved hot spot residues. J. Mol. Biol. 345, 1281-1294.

Kohlstaedt, L.A., Wang, J., Fiedman, J.M., Rice, P.A., Steitz, T.A., 1992. Crystal structure at $3.5 \AA$ resolution of HIV-1 reverse transcriptase complexed with an inhibitor. Science 256, 1783-1790.

Krajewski, K., Marchand, C., Long, Y.Q., Pommier, Y., Roller, P.P., 2004. Synthesis and HIV-1 integrase inhibitory activity of dimeric and tetrameric analogs of indolicidin. Bioorg. Med. Chem. Lett. 14, 5595-5598.

Krajewski, K., Long, Y.Q., Marchand, C., Pommier, Y., Roller, P.P., 2003. Design and synthesis of dimeric HIV-1 integrase inhibitory peptides. Bioorg. Med. Chem. Lett. 13, 3203-3205.

Lebon, F., LeClecq, M., 2000. Approaches to the design of effective HIV-1 protease inhibitors. Curr. Med. Chem. 7, 455-477.

Lobatón, E., Rodríguez-Barrios, F., Gago, F., Pérez-Pérez, M.J., De Clercq, E., Balzarini, J., Camarasa, M.J., Velázquez, S., 2002. Synthesis of $3^{\prime \prime}$ substituted TSAO derivatives with anti-HIV-1 and anti-HIV-2 activity through an efficient palladium-catalyzed cross-coupling approach. J. Med. Chem. 45, 3934-3945.

Loregian, A., Marsden, H.S., Palù, G., 2002. Protein-protein interactions as targets for antiviral chemotherapy. Rev. Med. Virol. 12, 239-262.

Loregian, A., Palù, G., 2005. Disruption of protein-protein interactions: towards new targets for chemotherapy. J. Cell. Physiol. 204, 750-762.

Lutzke, R.A., Plasterk, R.A., 1998. Structure-based mutational analysis of the C-terminal DNA-binding domain of human immunodeficiency virus type 1 integrase: critical residues for protein oligomerization and DNA binding. J. Virol. 72, 4841-4848.

Lutzke, R.A.P., Eppens, N.E., Weber, P.A., Houghten, R.A., Plasterk, R.H.A., 1995. Identification of a hexapaptide inhibitor of the human immunodeficiency virus integrase protein by using a combinatorial library. Proc. Natl. Acad. Sci. U.S.A. 92, 11456-11460.

Maroun, R.G., Gayet, S., Benleulmi, M.S., Porumb, H., Zargarian, L., Merad, H., Leh, H., Mouscadet, J.F., Troalen, F., Fermandjian, S., 2001. Peptide inhibitors of HIV-1 integrase dissociate the enzyme oligomers. Biochemistry $40,13840-13848$.

Merabet, N., Dumond, J., Collinet, B., Van Baelinghem, L., Bogetto, N., Ongeri, S., Ressad, F., Rebond-Ravaux, M., Sicisc, S., 2004. New constrained "nuclear tongs" designed to dissociate HIV-1 protease dimer. J. Med. Chem. 47, 6392-6400.

Morris, M.C., Robert-Hebmann, V., Chaloin, V.L., Mery, J., Heitz, F., Devaux, C., Goody, R.S., Divita, G., 1999. A new potent HIV-1 reverse transcriptase inhibitor. J. Biol. Chem. 274, 24941-24946.

Müller, B., Restle, T., Weiss, S., Gautel, M., Sczakiel, G., Goody, R.S., 1989. Co-expression of the subunits of the heterodimer of HIV-1 reverse transcriptase in Escherichia coli. J. Biol. Chem. 264, 1397513978.

Nicholson, L.K., Yamazaki, T., Torchia, D.A., Grzesiek, S., Bax, A., Stahl, S.J., Kaufman, J.D., Wingfield, P.T., Lam, P.Y., Jadhav, P.K., Hodge, C.N., Domaille, P.J., Chang, C.-H., 1995. Flexibility and function in HIV-1 protease. Nat. Struct. Biol. 2, 274-280.

Ockey, D.A., Gadek, T.R., 2002. Inhibitors of protein-protein interactions. Expert Opin. Ther. Pat. 12, 393-400. 
Oroszlan, S., Luftig, R.B., 1990. Retroviral proteinases. Curr. Top. Microbiol. Immunol. 157, 153-185.

Pandey, P.K., Kaushik, N., Talele, T.T., Yadav, P.N.S., Pandey, V.N., 2001. The $\beta 7-\beta 8$ loop of the $\mathrm{p} 51$ subunit in the heterodimeric (p66/p51) human immunodeficincy virus type 1 reverse transcriptase is essential for the catalytic function of the p66 subunit. Biochemistry 40, 95059512.

Pandey, P.K., Kaushik, N., Singh, K., Sharma, B., Upadhyay, A.K., Kumar, S., Harris, D., Pandey, V.N., 2002. Insertion of a small peptide of six amino acids into the $\beta 7-\beta 8$ loop of the p51 subunit of HIV-1 reverse transcriptase perturbs the heterodimer and affects its activities. BMC Biochem. 3, $18-31$.

Park, S.H., Raines, R.T., 2000. Genetic selection for dissociative inhibitors of designated protein-protein interactions. Nat. Biotechnol. 18, 847-851.

Pommier, Y., Cherfils, J., 2005. Intefacial inhibition of macromolecular interactions: nature's paradigm for drug discovery. Trends Pharmacol. Sci. 26, $138-145$.

Priestle, J.P., Fassler, A., Rosel, J., Tintelnot-Blomley, M., Strop, P., Grutter, M.G., 1995. Comparative analysis of the X-ray structures of HIV-1 and HIV-2 proteases in complex with CGP 53820, a novel pseudosymmetric inhibitor. Structure 3, 381-389.

Restle, T., Müller, B., Goody, R.S., 1990. Dimerization of human immunodeficiency virus type 1 reverse transcriptase. A target for chemotherapeutic intervention. J. Biol. Chem. 265, 8986-8988.

Restle, T., Müller, B., Goody, R.S., 1992. RNase H activity of HIV reverse transcriptases is confined exclusively to the dimeric forms. FEBS Lett. 300, 97-100.

Robinson Jr., W.E., McDougall, B., Tran, D., Selsted, M.E., 1998. Anti-HIV-1 activity of indolicidin, an antimicrobial peptide from neutrophils. Leukoc. Biol. 63, 94-100.

Rodríguez-Barrios, F., Pérez, C., Lobatón, E., Velázquez, S., Chamorro, C., San-Félix, A., Pérez-Pérez, M.J., Camarasa, M.J., Pelemans, H., Balzarini, J., Gago, F., 2001. Identification of a putative binding site for $\left[2^{\prime}, 5^{\prime}\right.$-bis- $O$-(tert-butyldimethylsilyl)- $\beta$-D-ribofuranosyl]-3' ${ }^{\prime}$-spiro$5^{\prime \prime}$-( $4^{\prime \prime}$-amino- $1^{\prime \prime}, 2^{\prime \prime}$-oxathiole- $2^{\prime \prime}, 2^{\prime \prime}$-dioxide)thymine (TSAO) derivatives at the p51-p66 interface of HIV-1 reverse transcriptase. J. Med. Chem. $44,1853-1865$

Schramm, H.J., Billich, A., Jaeger, E., Wakayama, H., Rucknagel, K.P., Arnold, G., Schramm, W., 1993. The inhibition of HIV-1 protease by interface peptides. Biochem. Biophys. Res. Commun. 194, 595600 .

Schramm, H.J., Boetzel, J., Buttner, J., Fritsche, E., Gohring, W., Jaeger, E., Konig, S., Thumfart, O., Wenger, T., Nagel, N.E., Schramm, W., 1996. The inhibition of human immunodeficiency virus proteases by "interface peptides". Antiviral Res. 30, 155-170.

Schramm, H.J., Nakashima, H., Schramm, W., Wakayama, H., Yamamoto, N., 1991. HIV-1 reproduction is inhibited by peptides derived from the $\mathrm{N}$ - and C-termini of HIV-1 protease. Biochem. Biophys. Res. Commun. $179,847-851$

Sluis-Cremer, N., Arion, D., Parniak, M.A., 2002. Destabilization of the HIV-1 reverse transcriptase dimer upon interaction with $N$-acyl hydrazone inhibitors. Mol. Pharmacol. 62, 398-405.
Sluis-Cremer, N., Dmitrienko, G.I., Balzarini, J., Camarasa, M.J., Parniak, M.A., 2000. Human immunodeficiency virus type 1 reverse transcriptase dimer destabilization by 1 -[spiro[ $4^{\prime \prime}$-amino- $2^{\prime \prime}, 2^{\prime \prime}$-dioxo- $1^{\prime \prime}, 2^{\prime \prime}$-oxathiole$5^{\prime \prime}, 3^{\prime}$-[2', $5^{\prime}$-bis-O-(tert-butyldimethylsilyl)- $\beta$-D-ribofuranosyl] $\left.]\right]-3$ ethylthymine. Biochemistry 39, 1427-1433.

Sluis-Cremer, N., Tachedjian, G., 2002. Modulation of the oligomeric structures of HIV-1 retroviral enzymes by synthetic peptides and small molecules. Eur. J. Biochem. 269, 5103-5111.

Smith, R., Brereton, I.M., Chai, R.Y., Kent, S.B., 1996. Ionization states of the catalytic residues in HIV-1 protease. Nat. Struct. Biol. 3, 946-950.

Song, M.-C., Rajesh, S., Hayashi, Y., Kiso, Y., 2001. Design and synthesis of new inhibitors of HIV-1 protease dimerization with conformationally constrained templates. Bioorg. Med. Chem. Lett. 11, 2465-2468.

Sourgen, F., Maroun, R.G., Frere, V.M., Bouziane, R.G., Auclair, C., Troalen, F., Fermandjian, S., 1996. A synthetic peptide from the human immunodeficiency virus type-1 integrase exhibits coiled-coil properties and interferes with the in vitro integration activity of the enzyme. Eur. J. Biochem. 240, $765-773$.

Tachedjian, G., Goff, S.P., 2003. The effect of NNRTIs on HIV reverse transcriptase dimerization. Curr. Opin. Investig. Drugs 4, 966-973.

Tachedjian, G., Orlova, M., Sarafianos, S.G., Arnold, E., Goff, S.P., 2001. Nonnucleoside reverse transcriptase inhibitors are chemical enhancers of dimerization of the HIV type 1 reverse transcriptase. Proc. Natl. Acad. Sci. U.S.A. 98, 7188-7193.

Tomasselli, A.G., Heinrikson, R.L., 2000. Targeting the HIV-protease in AIDS therapy: a current clinical perspective. Biochim. Biophys. Acta 1477, 189-214.

Toogood, P.L., 2002. Inhibition of protein-protein association by small molecules. Approaches and progress. J. Med. Chem. 45, 1543-1558.

Wang, J.Y., Ling, H., Yang, W., Craigie, R., 2001. Structure of a two-domain fragment of HIV-1 integrase: implications for domain organization in the intact protein. EMBO J. 20, 7333-7343.

Wlodawer, A., Miller, A., Jaskolski, M., Sathyanarayana, B., Baldwin, E., Weber, I., Selk, L., Clawson, L., Schneider, J., Kent, S., 1989. Conserved folding in retroviral proteases: crystal structure of a synthetic HIV-1 protease. Science 245, 616-621.

Wlodawer, A., Erickson, J.W., 1993. Structure-based inhibitors of HIV-1 protease. Annu. Rev. Biochem. 62, 543-585.

Zhang, Z., Poorman, R., Maggiora, L., Heinrikson, R., Kezdy, F., 1991. Dissociative inhibition of dimeric enzymes. Kinetic characterization of the inhibition of HIV-1 protease by its $\mathrm{COOH}$-terminal tetrapeptide. J. Biol. Chem. 266, 15591-15594.

Zhao, L., O'Reilly, M.K., Shultz, M.D., Chmielewski, J., 2003. Interfacial peptide inhibitors of HIV-1 integrase activity and dimerization. Bioorg. Med. Chem. Lett. 13, 1175-1177.

Zutshi, C.R., Chmielewski, J., 2000. Targeting the dimerization interface for irreversible inhibition of HIV-1 protease. Bioorg. Med. Chem. Lett. 10, 1901-1903.

Zutshi, R., Franciskovich, J., Shultz, M., Schweitzer, B., Bishop, P., Wilson, M., Chmielewski, J., 1997. Targeting the dimerization interface of HIV-1 protease: inhibition with cross-linked interfacial peptides. J. Am. Chem. Soc. $119,4841-4845$. 